NBER WORKING PAPER SERIES

PROFITABILITY OF FERTILIZER:

EXPERIMENTAL EVIDENCE FROM FEMALE RICE FARMERS IN MALI

\author{
Lori A. Beaman \\ Dean Karlan \\ Bram Thuysbaert \\ Christopher R. Udry \\ Working Paper 18778 \\ http://www.nber.org/papers/w18778
}

\author{
NATIONAL BUREAU OF ECONOMIC RESEARCH \\ 1050 Massachusetts Avenue \\ Cambridge, MA 02138 \\ February 2013
}

We thank an anonymous donor for funding the study. Nicole Mauriello, Henriette Hanicotte, Pierrick Judeaux, Camille Boudot and Yann Guy provided excellent research assistance. The views expressed herein are those of the authors and do not necessarily reflect the views of the National Bureau of Economic Research.

NBER working papers are circulated for discussion and comment purposes. They have not been peerreviewed or been subject to the review by the NBER Board of Directors that accompanies official NBER publications.

(C) 2013 by Lori A. Beaman, Dean Karlan, Bram Thuysbaert, and Christopher R. Udry. All rights reserved. Short sections of text, not to exceed two paragraphs, may be quoted without explicit permission provided that full credit, including $(\mathcal{C}$ notice, is given to the source. 
Profitability of Fertilizer: Experimental Evidence from Female Rice Farmers in Mali

Lori A. Beaman, Dean Karlan, Bram Thuysbaert, and Christopher R. Udry

NBER Working Paper No. 18778

February 2013

JEL No. O12,O13,Q12

\begin{abstract}
$\underline{\text { ABSTRACT }}$
In an experiment providing fertilizer grants to women rice farmers in Mali, we found that women who received fertilizer increased both the quantity of fertilizer they used on their plots and complementary inputs such as herbicides and hired labor. This highlights that farmers respond to an increase in availability of one input by re-optimizing other inputs, making it challenging to isolate the returns to any one input. We also found that while the increase in inputs led to a significantly higher level of output, we find no evidence that profits increased. Our results suggest that fertilizer's impact on profits is small compared to other sources of variation. This may make it difficult for farmers to observe the impact of fertilizer on their plots, and accordingly this affects their ability to learn about the returns to fertilizer and could affect their decision to adopt even in the absence of credit constraints.
\end{abstract}

Lori A. Beaman

Northwestern University 2001 Sheridan Rd, Rm 302

Department of Economics

Evanston, IL 60201

1-beaman@northwestern.edu

Dean Karlan

Department of Economics

Yale University

P.O. Box 208269

New Haven, CT 06520-8629

and NBER

dean.karlan@yale.edu
Bram Thuysbaert

Innovations for Poverty Action

101 Whitney Avenue

New Haven, CT 06510

bthuysbaert@poverty-action.org

Christopher R. Udry

Economic Growth Center

Yale University

Box 208269

New Haven, CT 06520

and NBER

udry@yale.edu 


\title{
Profitability of fertilizer: Experimental evidence from female rice farmers in Mali
}

\author{
By Lori Beaman, Dean Karlan, Bram Thuysbaert and Christopher Udry*
}

Intensified use of agricultural inputs, particularly fertilizer, is a possible route to improved agricultural productivity. Field trials of these technologies show substantial increases in yields, but typically are done on highly monitored experimental plots rather than by farmers themselves.

Returns to a certain technology might be quite different on real-world farms than on experimental farms, particularly when farmers must re-optimize multiple inputs in response to a new technology. Suri (2011) argues that not all farmers benefit from fertilizer use, despite there being high average returns. Behavioral biases may also prevent farmers from realizing their intentions to use fertilizer (Duflo, Kremer and Robinson, 2011). We use a simple field experiment to provide free fertilizer to women rice farmers in southern Mali to measure how farmers choose to use the fertilizer, what changes they make to their agricultural practices, and the profitability of this set of changes.

Rice is an important crop in the study area. It is almost exclusively farmed on women-controlled plots. The technology is low-input intensive and is "broadcast" farmed on non-irrigated flood planes: seeds are literally scattered loosely into a plot, rather than small plants transplanted from nurseries to rows in the plot. The rice production is mostly used for own consumption. Fertilizer is recommended by local agricultural extension agents and believed to substantially increase yields (Government of Mali, 2009). Nevertheless, only

\footnotetext{
* Beaman: Northwestern University, lbeaman@northwestern.edu; Karlan: Yale University, dean.karlan@yale.edu; Thuysbaert: Innovations for Poverty Action, bthuysbaert@poverty-action.org; Udry: Yale University, christopher.udry@yale.edu. We thank an anonymous donor for funding the study. Nicole Mauriello, Henriette Hanicotte, Pierrick Judéaux, Camille Boudot and Yann Guy provided excellent research assistance. All errors are our own.
}

about $30 \%$ of women use fertilizer, even with government price subsidies of around $33-43 \%$ (depending on the specific fertilizer).

TABle 1 -Fertilizer usage WORLDWide on Rice

\begin{tabular}{lcc}
\hline \hline & $\begin{array}{c}\text { Fertilizer } \\
\mathrm{kg} / \mathrm{ha}\end{array}$ & $\begin{array}{c}\text { Yield } \\
\mathrm{kg} / \mathrm{ha}\end{array}$ \\
\cline { 2 - 3 } World & 134 & 3,703 \\
Africa & 19 & 2,164 \\
Asia & 140 & 3,777 \\
North America & 184 & 6,615 \\
Latin America & 90 & 3,083 \\
Western Europe & 279 & 5,902 \\
\hline Notes & \multicolumn{2}{|}{} \\
1 Fertilizer usage as of 2002. \\
2 Rice yield based on 1994-96 data \\
3 Source: FAOStat and FAO (1996)
\end{tabular}

Africa's fertilizer rates and yields are lower than any other region. The women in our sample in southern Mali are above the average for fertilizer usage for Africa, using about $38 \mathrm{~kg} /$ ha of fertilizer, but they only achieve yields of around $1,600 \mathrm{~kg} / \mathrm{ha}$. In contrast, the irrigated zone within Mali has fertilizer per hectare rates of about 113 $\mathrm{kg} / \mathrm{ha}$ and achieves yields of about 4,500 $\mathrm{kg} / \mathrm{ha}$. The lack of water control in the study area is a significant limitation. A similar, if even larger, gap exists between Africa and the rest of the world for other cereal crops such as maize.

Our experiment had two treatment groups: those who received the full recommended quantity of fertilizer per hectare, and those who received half of the recommended quantity per hectare. We find that treatment increased the likelihood that women used fertilizer and increased the quantity of fertilizer used on their plots. They also report using more complementary inputs such as labor and herbicides. From a methodological perspective, this highlights a challenge in measuring the returns to a given input. In this case, farmers change other complementary inputs making 
it difficult to isolate the returns to fertilizer. This is a general and familiar point: a discrete change in the price or availability of one input may induce agents to re-optimize in potentially many dimensions; it is not in general possible to isolate the technical returns to varying that input alone. Instead, we are able to estimate the returns to a policy of fertilizer distribution. This basic tension between measuring returns to a specific input and determining the impact of a policy plagues most empirical studies in this literature.

As a consequence of the increased input use, rice output increases by $31 \%$ on average, an increase we measure with statistical precision. However, we do not measure any increase in agricultural profits. The point estimate of the effect of this increased input intensity on profits is very close to zero, but the precision of the estimates is low. The confidence interval includes the estimates of the most profitable quantity of fertilizer examined by Duflo, Kremer and Robinson (2008). However, the noise of the estimates in a real world environment highlights a potential constraint on farmers' fertilizer use: it may simply be difficult to learn about the returns to fertilizer for a particular farmer, given their land quality and other inputs, when the signal is small and there are large fluctuations in profits due to other shocks.

\section{Research design and data}

The fertilizer experiment was conducted in 23 villages in the district of Bougouni of southern Mali. In spring 2010, we conducted a census of female farmers in the selected villages, randomly sampled one woman per household and conducted a baseline survey. Detailed information was collected on agricultural activities, other economic activities, assets, consumption, expenditures, etc. Of the 416 respondents who were successfully interviewed, 383 cultivated rice in the agricultural season prior to the survey. These 383 women constitute our sample frame for the experiment.

Women were randomly assigned to one of 2 treatment cells or a control group: (1) 135 received the total recommended quantity per hectare, (2) 123 received half of the recommended quantity per acre, and (3) 125 were in the control group and received no fertilizer. ${ }^{1}$ We contacted various research institutes and extension agents within Mali to determine the treatment content ${ }^{2}$. The recommended level of fertilizer is roughly in line with the quantity of fertilizer used in North America and Western Europe. The half treatment is comparable to levels used in Asia for rice. We used our GPS measures of rice plot areas to determine individual farmers' plot sizes; the average rice plot is small, 0.22 of a hectare. Table 2 shows the mean transfers made, with the full treatment receiving on average 308.20 $\mathrm{kg}$ per hectare, and the half treatment receiving on average $156.20 \mathrm{~kg}$ per hectare ${ }^{3}$.

In late May 2010, we bagged and labeled the two fertilizer types and sent teams to the villages to distribute the fertilizer to the women in the treatment groups. We also provided a short, 30 minute explanation of how to use the fertilizer. No further training or monitoring was provided. A few months later, in August 2010, we conducted a first follow-up survey that focused on use of inputs. We conducted a second followup survey immediately after the harvest in December 2010. We were able to collect follow-up data for 378 primary respondents (out of 383 ).

\footnotetext{
${ }^{1}$ Randomization was done using a re-randomization routine that stratified by village and guaranteed that for all of the following variables the $p$ values for the comparisons of means between any of the 3 groups were larger than .5: whether or not there was an extended household, use of fertilizer, use of plough and an agricultural asset index. These baseline characteristics are included as controls in all regressions shown in Tables 3-4.

${ }^{2} \mathrm{As}$ a result of their advice we defined $200 \mathrm{~kg}$ of grain fertilizer (Complexe céréale, a particular type of NPK) and $100 \mathrm{~kg}$ of Urea per hectare as the full treatment amount. The original recommended amounts, consistent with Mali's agricultural subsidy program (Druilhe and Barreiro-Huré, 2012), were $100 \mathrm{~kg}$ of di-ammonium phosphate (DAP) and $150 \mathrm{~kg}$ of Urea. However, DAP was not available - a frequent problem - in the project area, so the local extension office recommended an alternative composition with fertilizer which was available.

${ }^{3}$ There is variation in the amounts received per hectare since for logistical reasons we put plot sizes into buckets (i.e. less than 1500 square meters, between 1500 and 2500 square meters, etc.) and provided the same quantity of fertilizer for all individuals in the same bucket and treatment group.
} 
TAble 2-Quantities and Value of Fertilizer transferred by treatment type

\begin{tabular}{|c|c|c|c|c|}
\hline & \multicolumn{2}{|c|}{ Half } & \multicolumn{2}{|c|}{ Full } \\
\hline & Mean & SD & Mean & $\mathrm{SD}$ \\
\hline Quantity of fertilizer (kg) & 32.09 & 21.77 & 65.71 & 45.04 \\
\hline Value of fertilizer (FCFA) & 8022.54 & 5442.93 & 16427.24 & 11259.78 \\
\hline Quantity of fertilizer per ha $(\mathrm{kg})$ & 156.04 & 37.36 & 308.20 & 80.49 \\
\hline Number of farmers & \multicolumn{2}{|c|}{123} & \multicolumn{2}{|c|}{135} \\
\hline
\end{tabular}

The experimental design differs from that of Duflo, Kremer and Robinson (2008) from Kenya in three main ways. First, in the Kenya experiment, each farmer divided a given plot into sections, applying fertilizer on some parts and not on others. Second, extension agents from the partner Kenya NGO helped farmers apply the fertilizer, monitored farmers, and assisted with harvest through crop cutting (which also lends itself to more precise measures of output). Third, in the Kenya experiment, other inputs were not formally measured ${ }^{4}$. In our experiment, women farmers were provided just the fertilizer and a short training on fertilizer. We returned months later to measure input use halfway through the agricultural cycle, and then finally after the harvest to measure output.

We thus report treatment effects from a policy of fertilizer distribution done without one-on-one monitoring nor extensive training. This design also reveals farmer choices when their endowments of fertilizer are exogenously increased. Farmers may adjust their behavior in response to the delivery of fertilizer in a variety of ways, such as transferring to others, storing, selling, as well as adjusting complementary inputs and effort.

\section{Results}

We investigate the effects of the fertilizer transfers on input usage, output and profits. Given that treatment assignment was

\footnotetext{
${ }^{4}$ In some of the trials, though, farmers were asked about the time spent weeding, and farmers reported weeding similar amounts on all segments of their plots. Dividing up one parcel into several parts, along with the instructions provided by the research team to not otherwise adjust their farming practices and the extension agents' monitoring, may have made farmers less likely to change other inputs.
}

random, the empirical strategy is straightforward. We estimate the following regression specification:

$$
\begin{aligned}
y_{i j t}= & \beta_{0}+\beta_{1} \text { half }_{i j t}+\beta_{2} \text { full }_{i j t} \\
& +\beta_{3} y_{i j(t-1)}+\beta_{4} x_{i j(t-1)}+\delta_{j}+\epsilon_{i j t},
\end{aligned}
$$

where $i$ represents farmers, $j$ represents villages, and $t$ represents time (two time periods, before and after). The coefficients of interest are $\beta_{1}$ and $\beta_{2}$, capturing the effect of the half and full treatment, respectively. $y_{i j(t-1)}$ is the lagged dependent variable, $x_{i j(t-1)}$ is the vector of baseline variables used in the randomization routine, and $\delta_{j}$ are village indicators since we stratified the randomization by village ${ }^{5}$. In Table A1 of the web appendix, we show tests for orthogonality of assignment to treatment and a set of input and outcome variables. For zero out of 9 variables are we able to reject the null hypothesis of equality at the $10 \%$ level.

\section{A. Inputs}

Table 3 looks at the impacts on inputs used on rice plots. All columns are estimates of the above specification where the dependent variable is identified in the column heading. Column (1) shows that treatment had a huge effect on the likelihood of usage: in control, $32 \%$ of women used fertilizer, whereas the two treatments had almost perfect compliance, generating treatment effects of 64 percentage points $(\mathrm{se}=0.04)$ for both the half and full treatments. The provision of fertilizer also dramatically increased the quantity of fertilizer used. The control group on average

\footnotetext{
${ }^{5}$ In addition, a dummy variable is included indicating if the value of the outcome variable is missing at baseline.
} 
TABle 3-Inputs (Women, Rice Plots)

\begin{tabular}{|c|c|c|c|c|c|c|c|c|}
\hline & \multicolumn{3}{|c|}{ Input use } & \multicolumn{5}{|c|}{ Input expenses } \\
\hline & $\begin{array}{c}\text { Use of } \\
\text { fertilizer }\end{array}$ & $\begin{array}{c}\text { Fertilizer } \\
\text { quantity } \\
\text { used } \\
(\mathrm{Kg})\end{array}$ & $\begin{array}{c}\text { Family labor } \\
\text { (days) }\end{array}$ & $\begin{array}{c}\text { Fertilizer } \\
\text { expenses } \\
(\mathrm{FCFA})\end{array}$ & $\begin{array}{c}\text { Herbicides } \\
\text { (FCFA) }\end{array}$ & $\begin{array}{c}\text { Expenses on } \\
\text { hired labor } \\
\text { (FCFA) }\end{array}$ & $\begin{array}{c}\text { Total input } \\
\text { expenses (excl. } \\
\text { fertilizer) } \\
\text { (FCFA) }\end{array}$ & $\begin{array}{c}\text { Total inputs } \\
\text { (incl. value of } \\
\text { fertilizer used) } \\
\text { (FCFA) }\end{array}$ \\
\hline & (1) & $(2)$ & $(3)$ & $(4)$ & (5) & $(6)$ & $(7)$ & $(8)$ \\
\hline Treatment (half) & $\begin{array}{c}0.64^{* * *} \\
(0.04)\end{array}$ & $\begin{array}{c}21.28^{* * *} \\
(4.10)\end{array}$ & $\begin{array}{c}2.84 \\
(4.32)\end{array}$ & $\begin{array}{c}-2412.91^{* * *} \\
(536.70)\end{array}$ & $\begin{array}{l}1012.54^{*} \\
(533.73)\end{array}$ & $\begin{array}{l}1075.15^{*} \\
(602.21)\end{array}$ & $\begin{array}{c}1705.06 \\
(1139.86)\end{array}$ & $\begin{array}{c}7061.32^{* * *} \\
(1641.05)\end{array}$ \\
\hline Treatment (full) & $\begin{array}{c}0.64^{* * *} \\
(0.04)\end{array}$ & $\begin{array}{c}32.91^{* * *} \\
(4.05)\end{array}$ & $\begin{array}{l}-4.73 \\
(4.27)\end{array}$ & $\begin{array}{c}-3011.97^{* * *} \\
(532.16)\end{array}$ & $\begin{array}{c}999.8^{*} \\
(527.71)\end{array}$ & $\begin{array}{c}2353.15^{* * *} \\
(594.93)\end{array}$ & $\begin{array}{c}3003.96^{* * *} \\
(1130.02)\end{array}$ & $\begin{array}{c}11450.61^{* * *} \\
(1627.02)\end{array}$ \\
\hline p-value: half $=1 / 2 *$ full & 0.00 & 0.17 & 0.16 & 0.05 & 0.27 & 0.85 & 0.84 & 0.35 \\
\hline $\mathrm{N}$ & 378 & 378 & 378 & 377 & 378 & 378 & 377 & 377 \\
\hline Mean of Control & 0.32 & 13.17 & 59.76 & 3585.16 & 3855.24 & 2967.74 & 9685.77 & 12993.70 \\
\hline SD of Control & 0.47 & 28.08 & 37.11 & 7871.52 & 4942.22 & 3632.80 & 10000.33 & 14399.81 \\
\hline
\end{tabular}

Notes:

1) Standard errors are in parentheses. ${ }^{*} \mathrm{p}<.10,{ }^{* *} \mathrm{p}<.05,{ }^{* * *} \mathrm{p}<.01$

2) Column (1) is a linear probability model while columns (2)-(8) show OLS estimates where the dependent variable is identified in the column heading. Also included in all specifications is the lagged dependent variable, an indicator for when the baseline value is missing, village fixed effects and the control variables used in the randomization routine (whether or not there is an extended household, use of fertilizer, use of plough and an agricultural asset index).

3) The dependent variable in (7) is the sum of those in (5) and (6), and expenses on seeds, ploughing, rental of carts, manure and chemicals other than fertilizer and herbicides such as e.g. insecticides and pesticides.

4) p-value: half $=1 / 2^{*}$ full reports the $p$ value of a Wald test that the impact of the half treatment is $1 / 2$ the size of the full treatment.

5) The mean and SD of control are values of the column heading variable at endline in only control villages.

used $13 \mathrm{~kg}$ of fertilizer, while the half treatment group used $21 \mathrm{~kg}$ more $(\mathrm{se}=4.10)$ and the full treatment group used $33 \mathrm{~kg}$ more $(\mathrm{se}=4.05)$. In the half treatment, the women used up most or all of the fertilizer given to them. The women in the full treatment used about $70 \%{ }^{6}$ of the fertilizer given to them, suggesting some fertilizer was either stored, sold or shared with other household members ${ }^{7}$. This strong response of fertilizer use on women's plots to grants

${ }^{6}$ The full treatment group used on average $46 \mathrm{~kg}$ of fertilizer, compared to an average of $66 \mathrm{~kg}$ given to women in that treatment group.

${ }^{7}$ We asked about inter-household sales and transfers of fertilizer in the first follow-up survey. Only 3 treatment households reported either selling or giving fertilizer to other households. We therefore believe that most of the unused fertilizer was used by other household members or stored. We did not observe an increase in fertilizer use on men's plots or other women's plots in 2010. However, men's plots are much larger on average than women's plots so it would be very difficult to detect a small, in relative terms, increase in fertilizer used. of fertilizer to women has important implications for our understanding of the economic organization of Malian households, and for the analysis of agricultural input and financial markets. Our focus in this paper, however, is on the impact of this increased fertilizer use on complementary inputs and on output.

We observe no change in the amount of family labor applied to women's rice plots (Table 3, Column 3). We find that a portion of the fertilizer grants replaces cash expenditure on fertilizer (Table 3, Column 4): women in the half treatment spent 2,413 FCFA less on fertilizer $(\mathrm{se}=537)$ and those in the full treatment spent 3,012 FCFA less $(\mathrm{se}=532)$.

Other inputs were crowded-in from the free fertilizer distribution. For herbicides (Table 3, Column 5), we find about a 1,000 FCFA increase (se= $530 \mathrm{FCFA})$ for both treatment groups, and expenses on hired labor increased, but less so: 1,075 FCFA 
$(\mathrm{se}=602)$ for the half treatment group and 2,353 FCFA ( $\mathrm{se}=595)$ for the full treatment group $^{8}$.

The total input expenses, excluding fertilizer and family labor, increased significantly for the full treatment group $(1,705$ FCFA, se $=1140$ for the half treatment; 3,004 FCFA, se $=1130$ for the full treatment). All in, Column 8 shows how the provision of fertilizer, and women's subsequent decisions on how to use the fertilizer and other inputs, affected total inputs. Total inputs, including the value of fertilizer used but excluding family labor, increased substantially, almost as much as the transferred amounts $(8,023$ FCFA transferred vs 7,061 FCFA increased inputs for the half treatment; 16,427 FCFA transferred vs 11,451 FCFA increased inputs for the full treatment).

\section{B. Output and profits}

The increases in input usage led to a considerable increase in the value of output, as shown in Column 1 of Table 4 . Output is valued at producer prices at the time of harvest, to avoid confounding a potential increase in profits from increased output with the returns to storage. The increase in output is 5,952 FCFA $(\mathrm{se}=3549)$ in the half treatment group and 11,046 FCFA $(\mathrm{se}=3505)$ in the full treatment group, compared to a control group mean of 35,920 FCFA, an increase of $17 \%$ and $31 \%$, respectively.

However, columns (2)-(4) show that we can not detect an increase in profits. Column (2) estimates a small but negative impact on profits $(-1,101 \mathrm{FCFA}, \mathrm{se}=3254$; 116 FCFA, se $=3227$, for the half and full treatments, respectively), calculated as the value of output minus the value of inputs other than family labor. We can then think of this definition of profits as including the family's wages for their labor plus the firm's profits. Column (3) also removes the value of family labor from profits ${ }^{9}$. Subsequently,

\footnotetext{
${ }^{8}$ We did not observe changes in expenses on other inputs such as seeds and ploughing.

${ }^{9} \mathrm{We}$ value family labor at a rate of 400 FCFA per day. As in most places in West Africa, labor markets
}

average profits in the control group are very low, and even negative on average. Column (4) uses a version of profits calculated as the value of output minus the value of just fertilizer in order to be comparable to that used by Duflo, Kremer and Robinson (2008), which overestimates the impact on profits because other purchased inputs increased due to treatment. In all three cases, we can not reject the null of no increase in profits. The confidence interval is large. A simple return on investment calculation, dividing the change in profits from the full treatment, as measured in column (2) of Table 4 , by the change in inputs from the full treatment (column (9) of Table 3), has a $90 \%$ confidence interval ranging from -0.48 to 0.46 . Therefore the rates of returns of the most profitable amounts of fertilizer in Duflo, Kremer and Robinson (2008) are contained in our confidence interval.

The large confidence interval of course partially reflects measurement error in the survey. But it also highlights that there is substantial variability in profits. For the full treatment, the upper bound of the $95 \%$ confidence interval for profits, as measured in Column 2, is still only .2 of a standard deviation. If the signal on the profitability of fertilizer is weak relative to the noise resulting from weather variability, it will be hard for farmers to learn about how much if any - fertilizer is optimal for them to use on their particular plot of land given other possible constraints they face on inputs (including labor, for example). Note that the experiment induced a large increase in the quantity of fertilizer used. A smaller increase in fertilizer, as would be more typical for farmers experimenting, would be even harder to detect ${ }^{10}$.

are relatively thin, and it is challenging to price family labor. This figure is based off of average wages paid to women laborers participating in work groups, which is the closest type of hired labor to family labor we observe in rural labor markets in southern Mali.

${ }^{10} \mathrm{We}$ also investigated treatment effect heterogeneity along the dimension of farmer experience/skill. As shown in the web appendix, we do not find evidence of treatment effect heterogeneity on output nor profits. 
Table 4-Output (Women, Rice Plots)

\begin{tabular}{lcccc}
\hline \hline & $\begin{array}{c}\text { Value output } \\
\text { (FCFA) }\end{array}$ & $\begin{array}{c}\text { Profits } \\
(\text { FCFA) }\end{array}$ & $\begin{array}{c}\text { Profits (subtracting } \\
\text { value of family labor) } \\
(\text { FCFA) }\end{array}$ & $\begin{array}{c}\text { Profits (subtracting } \\
\text { fertilizer costs only) } \\
\text { (FCFA) }\end{array}$ \\
\cline { 2 - 5 } & $(1)$ & $(2)$ & $(3)$ & $(4)$ \\
\cline { 2 - 5 } Treatment (half) & $5952.23^{*}$ & -1101.05 & -2446.13 & 593.56 \\
& $(3549.27)$ & $(3253.79)$ & $(3193.44)$ & $(3277.51)$ \\
Treatment (full) & $11045.78^{* * *}$ & -115.82 & 1458.83 & 2936.29 \\
& $(3504.60)$ & $(3226.97)$ & $(3167.06)$ & $(3237.35)$ \\
p-value: half $=1 / 2 *$ full & 0.89 & 0.71 & & 0.76 \\
N & 372 & 371 & 371 & 372 \\
Mean of Control & 35919.50 & 22971.13 & -1220.54 & 32649.88 \\
SD of Control & 31406.16 & 28880.84 & 27573.59 & 29660.41 \\
& & & & \\
\hline
\end{tabular}

Notes:

1) Standard errors are in parentheses. ${ }^{*} \mathrm{p}<.10,{ }^{* *} \mathrm{p}<.05,{ }^{* * *} \mathrm{p}<.01$

2) All columns show OLS estimates where the dependent variable is identified in the column heading. Also included in all specifications is the lagged dependent variable, an indicator for when the baseline value is missing, village fixed effects and the control variables used in the randomization routine (whether or not there is an extended household, use of fertilizer, use of plough and an agricultural asset index).

3) Family labor is valued at 400 FCFA per day in column (3).

4) The mean and SD of control are values of the column heading variable at endline in only control villages.

\section{Conclusion}

An experiment providing fertilizer grants to women rice farmers in Mali found that, first, women who received fertilizer increased both the quantity of fertilizer they used on their plots and complementary inputs such as herbicides and hired labor. This highlights that farmers respond to an increase in one input by re-optimizing other inputs, making it challenging to isolate the returns to any one input. Second, while the increase in inputs led to a significantly higher level of output, we find no evidence that profits increased. Our results suggest that fertilizer's impact on profits is small compared to other sources of variation. This may make it difficult for farmers to observe the impact of fertilizer on their plots, and accordingly this affects their ability to learn about the returns to fertilizer and could affect their decision to adopt even in the absence of credit constraints.

\section{REFERENCES}

\section{Druilhe, Zoé, and Jesús Barreiro-} Huré. 2012. "Fertilizer subsidies in sub-
Saharan Africa." FAO ESA Working Paper, No 12-04.

Duflo, Esther, Michael Kremer, and Jonathan Robinson. 2008. "How High are Rates of Return to Fertilizer? Evidence from Field Experiments in Kenya." American Economic Review, 98: 482488.

Duflo, Esther, Michael Kremer, and Jonathan Robinson. 2011. "Nudging Farmers to Use Fertilizer: Theory and Experimental Evidence from Kenya." American Economic Review, 101: 23502390 .

Food and Agriculture Organization of the United Nations. 2006. "Fertilizer use by crop." FAO Fertilizer and Plant Nutrition Bullet, No 17.

Government of Mali. 2009. "Bilan de la campagne agricole de l'Initiative Riz, 2008-2009." Ministère de l'Agriculture.

Suri, Tavneet. 2011. "Selection and Comparative Advantage in Technology Adoption." Econometrica, 79: 159-209. 